Produto \& Produção, vol 17 N 2, p 22-43, 2016

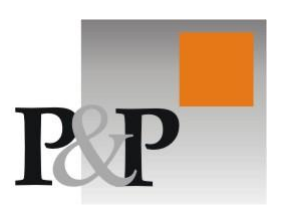

RECEBIDO EM 29/20/2013. ACEITO EM 22/03/2016.

\author{
Gabriela Scur \\ Centro Universitário da Fundação Educacional Inaciana Padre Sabóia de Medeiros - Centro \\ Universitário da FEI \\ gabriela@fei.edu.br \\ Marcel Miranda \\ Centro Universitário da Fundação Educacional Inaciana Padre Sabóia de Medeiros - Centro \\ Universitário da FEI \\ marcelgm@amcham.com.br
}

\title{
Importância do Módulo de Planejamento da Suíte de Manufatura nas Implementações do Sistema ERP
}

\section{RESUMO}

O Enterprise Resource Planning (ERP) foi criado a partir da necessidade de integração dos principais processos de negócios nas diversas áreas das empresas. A literatura aponta para a identificação do quanto a estrutura dos processos organizacionais é próxima das práticas de negócios formatadas no ERP. Todavia, o valor das funcionalidades relacionadas à manufatura (MRP e MRP II) para a competitividade da empresa que adota um sistema ERP, as dificuldades de implementação e de uso dessas funcionalidades, são ainda pontos pouco explorados. $\mathrm{O}$ objetivo deste artigo consiste em entender a importância que as empresas de manufatura dispensam aos módulos de planejamento do ERP. Foi elaborado, a partir da literatura, um modelo conceitual que propõe constructos e variáveis que afetam a visão de valor da empresa em relação ao uso dos módulos de planejamento da suíte de manufatura. Através de estudos de múltiplos casos observou-se que as empresas atribuem menor importância aos módulos de planejamento por questões relacionadas à: liderança corporativa; planejamento estratégico que permeie os níveis estratégico, tático e operacional; uma metodologia formal de gestão de operações; e adaptabilidade dos fundamentos de concepção do ERP aos processos de negócios da empresa.

Palavras-chave: ERP, planejamento de materiais, estratégia de operações.

\section{ABSTRACT}

The Enterprise Resource Planning (ERP) was created to integration of key business processes in different areas of the companies. The literature points to the identification of how the structure of organizational processes is close to the business practices in ERP. However, the value of functionalities related to manufacturing (MRP and MRP II) for the company's competitiveness adopting an ERP system as well as the difficulties of implementation and use of these functionalities are insufficient explored points. This paper aims to understand how important manufacturing planning modules are to the manufacturing companies, which implement an ERP. Based on a literature review a conceptual model has been prepared which proposes a list of constructs and 
variables that affect the company's value vision related to the manufacturing suite planning modules usage. In order to verify the theoretical model, a multiple case studies. The results indicate that companies lead less importance to manufacturing planning modules due issues related to: corporate leadership; strategic planning that permeate the strategic, tactical and operational levels; formal approach to an operations management methodology; and the adaptability level between ERP's design concepts and enterprise's business processes.

Key Words: ERP, materials planning, operations strategy.

\section{Introdução}

O ERP (Enterprise Resource Planning) foi criado a partir da necessidade de integrar com eficiência os principais processos de negócios nas diversas áreas das empresas (ZHANG et al., 2005; LAW e NGAI, 2007). A evolução do ERP teve lugar a partir de pacotes de mercado que eram voltados ao atendimento isolado dos processos de suprimentos e manufatura (DAVENPORT, 2000). Em meados dos anos 1990, este sistema se apresentava como uma solução abrangente que poderia trazer bons resultados para a eficiência operacional das empresas (SEDERA et al., 2003; McGINNIS e HUANG, 2007). Contudo, altos custos de implementação e de manutenção somados a retornos questionáveis (ZHANG et al., 2005), vêm fazendo do sistema ERP alvo de diversos estudos acadêmicos (SNIDER et al., 2009; WAGNER et al., 2006; BOTTA-GENOULAZ e MILLET, 2005; ZHANG et al., 2005; SEDERA et al., 2003) e questionamentos comerciais quanto às reais vantagens e desvantagens de sua adoção.

Apesar de ter emergido da evolução de sistemas integrados voltados ao controle das operações no chão de fábrica e ao planejamento de seus requisitos, as empresas de manufatura que implantam um ERP parecem não estabelecer as funcionalidades dedicadas à manufatura e seus processos complementares, como uma vantagem competitiva para suas operações.

De fato, através de uma base de clientes de uma empresa de ERP observou-se que de uma amostra de 112 clientes, 60 (54\%) são empresas de manufatura. Entre essas 60 empresas, 26 (43\%) não utilizam a suíte de MFG do ERP, outras 23 (38\%) não utilizavam os módulos de planejamento da suíte de MFG (MRP I e II), 9 (15\%) empresas utilizam apenas o MRP I e apenas 3 (4\%) empresas utilizam o MRP II. Como estes são dados de apenas uma empresa, embora uma das três maiores atuantes no Brasil, não são possíveis de generalizar para todas as empresas, mas seguramente mostram uma tendência de uso no Brasil.

Além disso, em sua maioria, o foco dos estudos realizados está voltado para a identificação do quanto a estrutura dos processos organizacionais é próxima das práticas de negócios formatadas no ERP (WAGNER et al., 2006; LAW e NGAI, 2007; SEDERA et al., 2003). Apesar desses estudos, entender qual o valor das funcionalidades relacionadas à manufatura para a competitividade da empresa que adota um sistema ERP, entender quais as dificuldades de implementação e de uso dessas funcionalidades e quais benefícios a empresa consegue auferir com sua utilização comparativamente a quais ela pretendia auferir, são ainda pontos pouco explorados. Ainda, foi identificada uma lacuna na literatura relacionada à importância da suíte de manufatura para as empresas de manufatura que implementam um ERP e suas funcionalidades de planejamento de materiais (MRP) e recursos de produção (MRP II). Desta forma, o objetivo principal do trabalho é analisar a importância que as empresas de manufatura, que implementam um ERP e sua suíte de manufatura, dispensam aos módulos de planejamento dessa suíte (MRP e MRP II).

O presente trabalho está estruturado em 06 partes, incluindo esta introdução. Na parte 2 e 3 são discutidos os conceitos e finalidades do ERP e da suíte de manufatura. Os procedimentos metodológicos estão apresentados na sessão 4. Já a sessão 5 traz os resultados obtidos a partir da pesquisa empírica. Por fim, na sessão 6 são apresentadas as conclusões do trabalho.

\section{O ERP e a suíte de manufatura}

O ERP é uma aplicação corporativa que permite às empresas integrarem e automatizarem os processos de negócios importantes para suas operações, oferecendo um modelo único de informações para toda empresa (WAGNER et al., 2006). 
Estudos acadêmicos mostram processos de implementação de sistemas ERP que foram fracassados (DAVENPORT, 1998; KONICKI, 2001; MARKUS et al., 2000). Várias empresas gastaram mais do que planejaram em função da resistência de gerentes e funcionários que não estavam preparados para as mudanças trazidas pelas aplicações corporativas (DAVENPORT, 2000). Além disso, constantemente depara-se com empresas, processos de negócios e usuários despreparados para a utilização deste tipo de ferramenta.

Quando corretamente implantado, o ERP propicia mudanças significativas nas corporações (DAVENPORT, 2000). Entre as mudanças mais significativas, sem dúvida, está a maior confiabilidade das informações que podem ser acessadas em tempo real. Também é significativa a diminuição do retrabalho, pois, a implementação do ERP proporciona a oportunidade de revisão dos processos de negócios considerando suas integrações e o fluxo de informações entre as diversas áreas. Essas integrações e o correto fluxo das informações são conseguidos com o auxílio das "melhores práticas de negócios" construídas dentro do ERP e o comprometimento dos funcionários, responsáveis por fazer a atualização sistemática dos dados que alimentam os módulos do ERP, e que, em última instância, fazem com que os diversos departamentos possam interagir com sincronismo objetivo.

Assim, as informações trafegam pelos módulos do ERP em tempo real, por exemplo, um pedido de vendas dispara o processo de fabricação e a necessidade de compras a partir da verificação dos estoques de insumos e de produto acabado, enviando e coletando informações de múltiplos departamentos (DAVENPORT, 2000).

O ERP permite que isso seja realizado a partir do banco de dados único com informações que interagem e se realimentam. Assim, a informação inicial sofre modificações sucessivas e assume novos significados e interpretações, ou seja, progride de acordo com uma sequência deliberadamente controlada, como o pedido de vendas que se transforma no produto final disponibilizado no estoque de produto acabado da empresa, pronto para ser enviado ao cliente através do controle do processo logístico, frequentemente também controlado dentro do ERP.

O foco nas necessidades dos clientes somente é efetivo se a função produtiva da empresa for preparada para atender àquelas necessidades (SHTUB, 1999). A suíte de Manufatura (MFG) de um ERP exerce um papel importante nesse preparo. Ligada à própria origem do ERP, conforme já mencionado nesse trabalho, essa suíte trata da operação da empresa, assumindo uma posição central em relação às demais suítes e módulos do ERP.

Shapiro (2007) afirma que a aplicação do ERP no processo decisório é um equívoco, pois este pode falhar na tarefa de proporcionar elementos analíticos para as decisões inerentes ao planejamento e otimização do uso de recursos. Embora normalmente façam parte da suíte de MFG do ERP mecânicas de planejamento consagradas do tipo MRP e MRP II, estas aplicações sozinhas não estão preparadas para considerar análises de cenários nem modelos de otimização. Neste debate é importante destacar que a suíte de MFG no contexto do ERP oferece, normalmente, elementos transacionais com aplicações de planejamento quantitativo que considera análise univariada (demanda) relacionada às necessidades de recursos para produção, porém, necessita ser complementada por aplicações de planejamento da cadeia de suprimentos em que técnicas de análises multivariadas, de modelagem e análise de decisão podem ser realizadas visando otimizar a utilização desses recursos.

Nessa posição torna-se dependente das informações e processos de outras suítes bem como responsável pela alimentação dessas mesmas suítes com as informações relativas à operação, dando sequência coordenada a diversos processos de negócios. Por exemplo, a suíte de Manufatura (MFG) alimenta a suíte de Distribuição \& Logística (D\&L) com as necessidades de materiais para o processo produtivo e depende das informações sobre as quantidades existentes nos estoques, oferecidas pelo módulo de Estoques, ou quantidades em trânsito oferecidas pelo módulo de Logística, ambos dentro da suíte de D\&L. Também alimenta a suíte Financeira (FIN) com as bases para contabilização dos custos de mão de obra direta, gastos gerais de fabricação e consumo de matérias primas incorridos no processo produtivo. É, portanto, um importante elo da cadeia de valor da empresa, um importante elo da cadeia de suprimentos.

\section{Implantação do sistema ERP}


A implementação de sistemas ERP comumente é capitaneada pela área de sistemas das empresas, porém o ERP é uma classe de sistema corporativo que tem seu foco nas áreas de negócios. $\mathrm{O}$ ERP tem o potencial de suportar os processos de negócios das empresas e melhorar significativamente a capacidade da empresa em inová-los (SRIVARDHANA e PAWLOWSKI, 2007), trazendo melhorias no controle de cada processo, facilitando o sincronismo e garantindo a sequência entre as tarefas que compõem cada processo operacional necessário para que a empresa atinja seus objetivos.

A implantação do ERP deveria ser capitaneada pelas áreas de negócio com o apoio da área de TI. De certa forma, a implantação acaba por envolver todas as áreas da empresa, mas, constantemente com um enfoque de tarefa e não de um processo transformador como, de fato, tem potencial de ser. $\mathrm{O}$ projeto de implementação deveria ser tratado como um processo desde sua intenção até o seu término, o que inclui a implantação - após o término do projeto de implementação segue-se a fase de manutenção (ou pós-implementação) onde se deve entender o "nunca" como momento do término (McGINNIS e HUANG, 2007).

Nessa abordagem defende-se o fato de que para proceder a esse tipo de implementação, as pessoas e os processos da empresa serão expostas a revisões. Revisão de conceitos, revisão de formas de atuação, revisão de maneiras de pensar, revisão de maneiras de fazer, revisão de maneiras de conduzir, revisão de maneiras de medir, revisão da forma de gerir as operações da empresa. Porém, o enfoque de "tarefa" e não de "projeto transformador" acaba por turvar os resultados obtendo-se uma implantação com falhas que comprometem o potencial de retorno de uma ferramenta de gestão como um ERP.

Em um projeto de implementação de um sistema ERP, é necessária a adoção de uma metodologia para fazer frente à complexidade da atividade. Normalmente, o primeiro passo é determinar a necessidade da adoção de uma ferramenta de gestão desse tipo, ou seja, determinar a adoção de um software corporativo.

Apesar de que softwares desse tipo podem ser aplicados a diversas indústrias, para efeito desse trabalho é dado foco apenas na indústria de manufatura, tendo a suíte de manufatura como principal protagonista deste estudo. Entre as grandes empresas de manufatura globalizadas, poucas não o adotaram (DAVENPORT, 2000; SNIDER et al., 2009). Pode-se citar o exemplo atual de uma montadora japonesa de veículos (esse exemplo foi vivenciado pelo autor em suas atividades profissionais) que, até o momento dos levantamentos desse trabalho, dá suporte aos seus processos de negócios através de sistemas elaborados internamente, ou seja, os chamados custom-built, e não através de pacotes de mercado. Porém, se há o entendimento que o sistema ERP, conforme mencionado, é um conjunto de programas agrupados em rotinas integradas que - através de uma instância única de dados - controla de maneira lógica e deliberadamente direcionada as informações dos processos de negócios da empresa (BOTTA-GENOULAZ, MILLET, 2005). Desta forma, ter sido elaborado por uma empresa especializada do tipo SAP, ORACLE e TOTVS ou por empresa não especializada que o construiu para seu próprio uso, não é relevante para efeito desse trabalho. Há algum tempo as pequenas e médias empresas estão seguindo os passos das grandes que implementaram um ERP e decidindo também pela implementação de sistemas desse tipo. Enquanto grandes empresas iniciaram esse movimento a partir dos anos 1990, uma parcela das pequenas e médias empresas iniciou esse movimento somente a partir da segunda metade da década de 2000 (SNIDER et al., 2009; VOGEL; WOOD JUNIOR, 2012).

Para se ter uma ideia da importância das PMEs no Estado de São Paulo onde a pesquisa for desenvolvida, em 2013, de acordo com dados do Ministério do Trabalho e Emprego (RAIS-MTE) consolidados pelo Fiesp (2014) contava com 92.954 estabelecimentos da indústria de transformação de pequeno e médio porte, os quais eram responsáveis por cerca de $69 \%$ dos empregos formais do Estado. Conforme critério adotado por estas instituições, são classificadas como pequena e média empresa industrial aquelas que possuem entre $20-99$ e 100 a 499 funcionários formais, respectivamente. Pertencem a esse grupo as empresas participantes deste estudo por se tratar de um grupo de empresas manufatureiras que recentemente implantaram o ERP.

Alguns elementos são necessários em projetos de implementação de ERP; são eleitos "usuários chaves" que, normalmente, conhecem o processo atual da empresa, e se supõem conhecer as necessidades da empresa em relação a um determinado processo de negócio. Um processo de negócio 
é um conjunto de tarefas logicamente relacionadas realizado para alcançar um resultado de negócios definido (DAVENPORT e SHORT, 1990; SRIVARDHANA e PAWLOWSKI, 2007).

Nesse ponto, pode ser que o profissional escolhido para participar do projeto de implementação, conheça muito daquela forma de atender ao processo de negócio mas isso não significa que a tal forma seja a mais adequada e nem tão pouco que seja a forma suportada pelo ERP que se quer implantar. Também não quer dizer que a empresa esteja fazendo a coisa certa.

Para se obter sucesso no processo de implantação do sistema ERP, é fundamental que a empresa atenda aos requisitos levantados pela literatura (DAVENPORT, 1998; HECHT, 1997; SOUZA, 2000; LAUDON e LAUDON, 2007; LOZINSKY, 1996; MENDES e ESCRIVÃO FILHO, 2002; ZHANG et al., 2005), a saber:

a) Padronizar os procedimentos - definir e consolidar as regras de negócios;

b) Reduzir os custos relacionados à falta de coordenação entre as áreas/atividades da empresa;

c) Reduzir a mão-de-obra decorrente da simplificação de processos administrativos e geração de relatórios gerenciais; decisão;

d) Disponibilizar informações de qualidade em tempo real para a tomada de

e) Eliminar as inconsistências entre diferentes sistemas e entre diferentes processos;

f) Integrar as informações - base única de dados;

g) Reduzir os custos da área de TI;

h) Reduzir os custos com treinamento, pois a empresa utilizará um sistema único, eliminando a utilização de sistemas específicos para cada área; e

i) Atualizar o parque tecnológico.

Bancroft, Seip e Sprengel (1998) destacam o desafio da participação dos usuários no processo de implementação, bem como a transferência dos conhecimentos e das responsabilidades do novo sistema para os usuários.

Alguns estudos (KRASNER, 2000; LAUDON; LAUDON, 2007; MENDES; ESCRIVÃO FILHO, 2002; SOUZA, 2000) também apontam os fatores de insucesso do processo de implantação de um sistema ERP. São eles:

a) Necessidade de comprometimento das equipes da empresa com o novo modelo de sistema de informação;

b) Alto volume de investimento, por vezes por longo período, e investimentos em atualização;

c) Mudança de responsabilidades e funções para alguns cargos dentro da empresa;

d) Dificuldade em implantar a integração proposta pelo novo sistema;

e) Ausência de plano e administração de testes integrados;

f) Não aplicação de conhecimentos adquiridos em processos anteriores;

g) Complexidade na customização (adequação do ERP aos processos de negócios) do sistema;

h) Falha na comunicação entre os usuários;

i) Interface do sistema não amigável;

j) Desconhecimento do sistema ERP e do negócio da empresa;

k) Falta de treinamento da equipe de TI e dos usuários;

1) Falta de comprometimento dos usuários; e

m) Falta de comprometimento da alta direção.

Law e Ngai (2007) listam os fatores críticos para a implantação como justificativas relativas ao projeto, ou seja, as razões para a implementação; riscos e aderência dos processos de negócios aos processos do ERP.

Em relação à aderência, Hong e Kim (2002), encontraram evidências empíricas entre o relacionamento do sucesso da implantação e a aderência dos processos organizacionais com as "melhores práticas" contidas no ERP.

Assim, o ERP é uma aplicação corporativa que deve integrar e automatizar os processos de negócios das empresas, os quais são fundamentais para suas operações. Para operar corretamente, esse 
sistema é dependente da qualidade dos processos executados e das informações neles transacionadas, isto é, da qualidade da execução das tarefas e atividades formadoras dos processos de negócios e suas informações relacionadas.

Schniederjans e Kim (2003) argumentam que que a relação de sucesso na implantação do sistema ERP está ligada a fatores similares àqueles vindos da prática da Gestão da Qualidade Total (TQM).

O TQM é um modelo de gestão que proporciona vantagem competitiva quando implantado corretamente. Porém, as condições de mercado existentes no momento de sua implementação não permanecem constantes e, portanto, as condições competitivas também se alteram no decorrer do tempo, fazendo com que a execução dos processos com qualidade seja um "critério de qualificação", deixando para a inovação o papel de "critério ganhador de pedido" (PRAJOGO; SOHAL, 2001).

Essa relação também existe para o ERP na medida em que os concorrentes também têm acesso ao software e podem, a qualquer momento, implementá-lo tornando-o também um "critério de qualificação" e não um "critério ganhador de pedido. Contudo, a incorreta implantação tanto do TQM quanto do ERP traz desvantagens competitivas para a empresa na medida em que deixa de propiciar os benefícios esperados, ao mesmo tempo em que incorreram nos custos dos esforços de implementação.

Alguns autores (OOI; ARUMUGAM; TEH, 2008; JUN; CAI; SHIN, 2006; ZAKUAN et al., 2008; PRAJOGO; SOHAL, 2001; NJIE; FON; AWOMODU, 2008; ARUMUGAM; OOI, 2008; OOI, 2009) propõe para o TQM uma lista de constructos que expõem sua multidimensionalidade, a saber: Comprometimento e Liderança do alto escalão; Foco no cliente e na sua satisfação; Qualidade da informação e da sua análise; Desenvolvimento dos Recursos Humanos; Gestão do Planejamento Estratégico; Gestão da qualidade dos fornecedores; Qualidade dos resultados; Qualidade assegurada dos produtos.

Relacionando os fatores de sucesso e insucesso na implantação do ERP com os constructos do TQM, é possível determinar os pontos de convergência em cada uma das dimensões. A figura 1 resume as relações. 


\begin{tabular}{|c|c|c|}
\hline Constructos & Finalidade no TQM & Finalidade no ERP \\
\hline $\begin{array}{l}\text { Liderança e } \\
\text { comprometimento da } \\
\text { alta administração }\end{array}$ & $\begin{array}{c}\text { O grau de visibilidade e suporte que } \\
\text { os gestores propiciam num } \\
\text { ambiente de implantação do TQM } \\
\text { é significativo para o sucesso do } \\
\text { projeto de TQM }\end{array}$ & $\begin{array}{c}\text { O grau de } \\
\text { comprometimento dos } \\
\text { gestores com a implantação } \\
\text { do ERP é crítico para o } \\
\text { sucesso da implantação do } \\
\text { ERP } \\
\end{array}$ \\
\hline Foco no Cliente & $\begin{array}{c}\text { A satisfação dos clientes é um } \\
\text { objetivo fundamental. Desenvolver } \\
\text { e gerenciar sólidos relacionamentos } \\
\text { de longo prazo com os clientes. } \\
\text { Conhecer as necessidades atuais e } \\
\text { expectativas futuras dos clientes. }\end{array}$ & $\begin{array}{l}\text { Dar foco na satisfação dos } \\
\text { clientes. Suportar os } \\
\text { processos de negócios da } \\
\text { empresa que fazem } \\
\text { interface com os clientes, } \\
\text { oferecendo informações de } \\
\text { qualidade e agilidade na } \\
\text { entrega dos produtos } \\
\end{array}$ \\
\hline $\begin{array}{l}\text { Planejamento } \\
\text { Estratégico }\end{array}$ & $\begin{array}{l}\text { O grau de clareza que a empresa } \\
\text { tem de sua visão, missão, } \\
\text { planejamento de longo prazo e } \\
\text { políticas de qualidade }\end{array}$ & $\begin{array}{c}\text { Direcionamento coordenado } \\
\text { dos esforços com conexão } \\
\text { entre os níveis Corporativo, } \\
\text { Tático e Operacional }\end{array}$ \\
\hline Informação e Análise & $\begin{array}{c}\text { O grau em que dados e } \\
\text { informações são coletados e } \\
\text { analisados para o objetivo de } \\
\text { melhoria da qualidade } \\
\end{array}$ & $\begin{array}{c}\text { O nível de qualidade das } \\
\text { informações que são } \\
\text { oferecidas e extraídas do } \\
\text { ERP }\end{array}$ \\
\hline Gestão de Processos & $\begin{array}{c}\text { Enfase na agregação de valor aos } \\
\text { processos, aumentando os níveis de } \\
\text { qualidade e implantando programas } \\
\text { de redução de desperdício de } \\
\text { tempo e custos em todos os } \\
\text { processos internos da empresa }\end{array}$ & $\begin{array}{l}\text { Avaliar a compatibilidade } \\
\text { entre a estratégia } \\
\text { empresarial e a lógica dos } \\
\text { negócios à luz das } \\
\text { "melhores práticas de } \\
\text { negócios" embutidas no } \\
\text { ERP } \\
\end{array}$ \\
\hline $\begin{array}{c}\text { Gestão de Recursos } \\
\text { Humanos }\end{array}$ & $\begin{array}{l}\text { Um processo de gestão de } \mathrm{RH} \text { com } \\
\text { alto grau de abrangência, projetado } \\
\text { e integrado à estratégia da empresa }\end{array}$ & $\begin{array}{c}\text { Comprometimento das } \\
\text { equipes da empresa com o } \\
\text { novo modelo de sistema de } \\
\text { informação aliado a um } \\
\text { plano de gestão de RH } \\
\text { orientado a manter uma } \\
\text { força de trabalho treinada e } \\
\text { satisfeita. }\end{array}$ \\
\hline
\end{tabular}

Figura 1: Relacionamento entre os constructos do TQM e os fatores de sucesso/insucesso da implantação do ERP. Fonte: Adaptado de Ooi (2009)

Em sua pesquisa na indústria eletroeletrônica da Malásia, onde foram entrevistados 520 funcionários de três empresas diferentes, Ooi, Arumugam e Teh (2008) buscaram identificar quais práticas do TQM produziriam melhores efeitos na produtividade e satisfação dos empregados. Identificaram que nem todas as práticas do TQM alcançavam sucesso nesse sentido. A cultura organizacional e o espírito de trabalho em equipe apresentaram-se como práticas mais eficazes em relação a esses objetivos. O papel da alta administração com o projeto de implementação do TQM, também se apresentou como um fator crítico para o sucesso de sua implantação (JUN; CAI; SHIN, 2006; OOI; ARUMUGAM; TEH, 2008).

Nos projetos de implementação do ERP há a possibilidade de transferência de conhecimentos entre os profissionais da consultoria externa e os funcionários da empresa. A transferência de conhecimento e de práticas de negócios transforma a maneira com que a empresa é administrada e torna-a dependente dessas práticas e conhecimentos.

Para que os processos de negócios sejam efetivos diante das melhores práticas de negócios, (benchmarking) contidas no ERP, é necessário que sejam executados de acordo com os procedimentos estabelecidos. Para tanto, é necessário que sejam considerados alguns fatores no projeto de implementação do ERP. Esses fatores vêm das práticas do TQM, consistem no comprometimento da alta direção com o projeto e nas práticas de RH (que levam à satisfação e lealdade dos funcionários) 
(JUN; CAI; SHIN, 2006) retendo assim o conhecimento tácito adquirido durante o projeto de implementação.

Por se tratar de sistema de informações, o ERP sofre o paradigma de ser visto como tecnologicamente complexo, uma vez que, na sua implementação existem etapas de escolha e de disponibilização de infraestrutura de TI. Entretanto, a liderança do projeto ERP pela área de TI parece caracterizar-se como um erro estratégico da empresa. Espera-se que o projeto ERP, tal qual o projeto de TQM, tenha na alta direção seu patrocinador. Visto que a área de TI atua como suporte ao negócio, e não tem a exata dimensão do potencial de importância que o sistema ERP tem para a empresa, suas operações e seu diferencial competitivo.

\section{Procedimentos metodológicos}

Um dos métodos de pesquisa qualitativa recomendados para o estudo de uma situação em particular, examinando detalhadamente o ambiente onde ocorre é o estudo de caso (GODOY, 1995). Esse método é também adequado para estudos em que a questão de pesquisa está relacionada à "como" e "por que" certos fenômenos ocorrem (YIN, 2005). Em gestão de operações, Karlsson (2009) aponta o estudo de casos como sendo um poderoso método de pesquisa, particularmente para estudos exploratórios e para teste, extensão e/ou refinamento de teorias existentes.

O estudo de caso é um estudo de natureza empírica que investiga um determinado fenômeno, geralmente contemporâneo, dentro de um contexto real de vida, quando as fronteiras entre o fenômeno e o contexto em que ele se insere não são claramente definidas, além de quando os comportamentos relevantes não podem ser manipulados (YIN, 2010).

Desta forma, justifica-se o uso da metodologia qualitativa, através do método estudos de caso, neste estudo por se tratar de uma pesquisa que busca esclarecer o motivo pelo qual uma decisão ou um conjunto de decisões foram tomados, como foram implantadas e com quais resultados alcançados (YIN, 2010). Eisenhardt (1989) sugere que o número de casos varie entre quatro e dez, pois acima disso o processamento dos dados por parte do pesquisador passa a ser comprometido em função da quantidade de informações levantadas e, abaixo de quatro, torna-se difícil gerar teorias coesas. Baseado nas premissas levantadas na revisão bibliográfica, foi criada a figura 2 que mostra a relação dos constructos (Liderança e Comprometimento da Alta Administração, Planejamento Estratégico, Modelo de Gestão de Operações e Adaptabilidade do ERP) com as variáveis de gestão corporativa (Unidade de Comando Corporativo; Efetividade do Direcionamento Estratégico; Estrutura de Gestão das Operações; e Nível de Aderência do ERP aos Processos de Negócios da Empresa) são determinantes para a ocorrência desses fenômenos (lacuna de utilização da suíte de MFG e falta de motivação na aplicação do MRP I e II), conforme exposto anteriormente. A figura 2 apresenta o modelo conceitual utilizado na condução da pesquisa. 


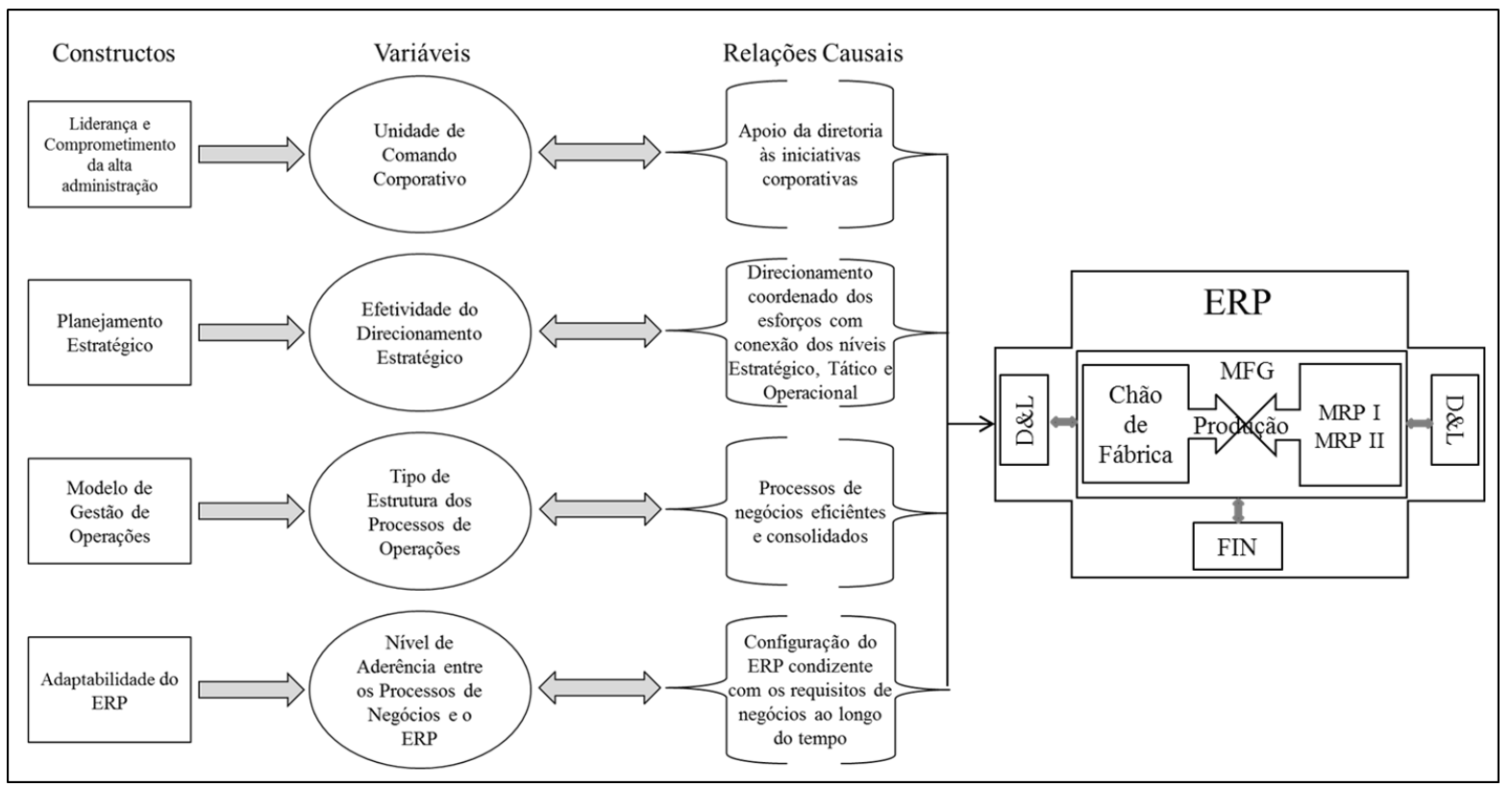

Figura 2 - Modelo conceitual do projeto de pesquisa

A partir deste modelo conceitual foi construído o roteiro de entrevista. Esse roteiro foi estruturado em blocos correspondentes às variáveis exposta no modelo, conforme apêndice 1.

Voss, Tsikriktsis, Frohlich (2002) argumentam que a coleta de dados seja feita por meio da combinação de diferentes métodos, que podem ser entrevistas, questionários, observações, análises documentais, etc. Esta combinação é conhecida como triangulação e permite obter diferentes pontos de vista sobre um mesmo fenômeno. Nesse trabalho foram utilizadas diversas fontes de evidências para validar os constructos, a saber:
a) A base de dados contendo 112 empresas;
b) Conversas com profissionais da área;
c) Conhecimento profissional do autor;
d) Documentos de projetos e de processos ligados a implementações de ERP;
e) Estudos de casos com 4 empresas.

\subsection{A seleção dos casos}

Para atender aos objetivos do artigo as empresas investigadas têm seu foco de negócio (core business) na manufatura. Porém, deliberadamente foram escolhidas empresas de diferentes portes, mercados de atuação e nacionalidades. Essa escolha pretende dar a pesquisa isenção de tendências, ou seja, não se tem intenção de relacionar as razões de sucesso ou fracasso das implantações da suíte de manufatura, ao porte da empresa, seu mercado de atuação ou sua nacionalidade. Ao contrário, defende-se aqui que independente dessas características, as empresas podem tender ao sucesso ou ao fracasso de suas implantações dessa suíte em função do modelo conceitual proposto nesse trabalho.

O estudo busca evidências da fraca obtenção de benefícios com a implementação da suíte de manufatura do ERP, naquelas empresas em que a liderança corporativa se apresente estratificada; em que não exista um processo de planejamento estratégico formal e que conecte os níveis estratégico, tático e operacional; em que não exista um modelo formal de gestão de operações; e onde a aderência entre os processos de negócios e o ERP esteja comprometida.

A seleção da população para realização dessa pesquisa incluiu, portanto, empresas de manufatura com atuação no Brasil, que tenham implementado a suíte de manufatura (MFG) do ERP JD Edwards da fabricante americana Oracle. Essa população foi deliberadamente selecionada por três razões: Primeiro, atender à questão de pesquisa relativa ao entendimento da utilização dos módulos de planejamento da suíte de MFG do ERP. Segundo, fixar a variável "pacote ERP" com intuito de simplificar o número de variáveis para análise, visto que, se outros pacotes fossem incluídos, considerações comparativas entre as funcionalidades de cada pacote teriam que ser elaboradas para a complementação da pesquisa, não sendo esse o objetivo desse trabalho. 
O estudo exploratório incluindo outros pacotes e a comparação entre eles atestando a proposição do trabalho, são oportunidades para pesquisas futuras. A terceira razão está relacionada à possibilidade de acesso às informações da população selecionada, tendo em vista a atuação profissional do autor que trabalhou na extinta JD Edwards e presta consultoria para diversas empresas que utilizam esse e outros softwares ERP.

Através de seus contatos com a fabricante do ERP, os autores tiveram acesso a um documento contendo a base de clientes da extinta JD Edwards e, num exame preliminar do documento, fez as seguintes observações: de uma amostra de 112 clientes, 60 (54\%) são empresas de manufatura. Entre essas 60 empresas, 26 (43\%) não utilizam a suíte de MFG do ERP, outras 23 (38\%) não utilizavam os módulos de planejamento da suíte de MFG (MRP e MRP II), 9 (15\%) empresas utilizam apenas o MRP e apenas 3 (4\%) empresas utilizam o MRP II.

Dentro da população selecionada, várias empresas possuem as licenças de uso dos módulos de planejamento da suíte de MFG e algumas realizaram o esforço de implementação desses módulos. A população inicial composta por 112 empresas foi reduzida a 23 devido aos critérios de seleção (implementação e uso da suíte de MFG na subsidiária ou sede brasileira). Destas 23, foram selecionadas empresas que pudessem representar tipos distintos de estratégias de produção e nacionalidade, chegando-se a um número de 17 empresas. Dessas 17, conseguiu-se contato com gestores de 10 empresas, que receberam o convite para participar da pesquisa, sendo que 4 aceitaram participar.

Daquelas 10 empresas convidadas, 6 não utilizam os módulos de planejamento de materiais e recursos de produção (MRP ou MRP II) e dentre as 4 que utilizam, apenas 2 fazem uso do planejamento dos recursos de produção (MRP II). Dentre as quatro (4) empresas que aceitaram participar da pesquisa, apenas uma (1) utiliza o módulo de planejamento de materiais. Nenhuma utiliza o módulo de planejamento de recursos de produção (MRP II).

Nas empresas selecionadas, foram contatados profissionais em cargo de diretoria, gerência e de supervisão nas áreas envolvidas no processo de implementação do ERP e principalmente envolvidos nas áreas de operações, sendo esse o último critério de seleção. Ressalta-se, que foi colocada a condição de não divulgação do nome das empresas, tendo em vista que as mesmas consideram estratégicos os dados a serem discutidos neste artigo.

A figura 3 apresenta as empresas que aceitaram participar do estudo.

\begin{tabular}{|c|l|l|c|}
\hline $\begin{array}{c}\text { Denominação da } \\
\text { Empresa }\end{array}$ & \multicolumn{1}{|c|}{ Mercado de Atuação } & Nacionalidade & $\begin{array}{c}\text { Atuação no } \\
\text { Brasil desde }\end{array}$ \\
\hline HolyBible & fabricante de livros religiosos & Anglo-Brasileira & 1975 \\
\hline InovativEduc & $\begin{array}{l}\text { fabricante de material } \\
\text { educacional }\end{array}$ & Brasileira & 1999 \\
\hline CropNutri & fabricante de fertilizantes & Norte Americana & 2010 \\
\hline TechTissue & $\begin{array}{l}\text { fabricante de tecidos e } \\
\text { revestimentos sintéticos }\end{array}$ & Brasileira & 1964 \\
\hline
\end{tabular}

Figura 3 - Empresas integrantes da pesquisa

As empresas que aceitaram participar apresentaram diferenças em suas áreas de atuação, seus portes, tempo de uso do ERP, forma de aplicar a suíte de manufatura, uso e motivação de uso dos módulos de planejamento da suíte, condições de relacionamento com os constructos e nacionalidades. A figura 4 apresenta os profissionais entrevistados. 


\begin{tabular}{|c|c|c|c|c|}
\hline Empresa & Cargo atual & $\begin{array}{c}\text { Cargo à época da implantação } \\
\text { do ERP }\end{array}$ & $\begin{array}{c}\text { Quantidade } \\
\text { de encontros }\end{array}$ & $\begin{array}{r}\text { Total de } \\
\text { encontros }\end{array}$ \\
\hline \multirow{4}{*}{ HolyBible } & Coordenador do ERP & Coordenador Técnico do Projeto & 3 encontros & \multirow{4}{*}{$\begin{array}{c}9 \\
\text { encontros }\end{array}$} \\
\hline & $\begin{array}{l}\text { Assessor de Tecnologia da } \\
\text { Informação (CIO) }\end{array}$ & Gerente do Projeto & 2 encontros & \\
\hline & Gerente Industrial & Usuário Chave para Manufatura & 2 encontros & \\
\hline & Gerente de Logística & $\begin{array}{l}\text { Usuário Chave para Materiais e } \\
\text { Logística }\end{array}$ & 2 encontros & \\
\hline \multirow{3}{*}{ InovativEduc } & Coordenador do ERP & Não estava na empresa & 2 encontros & \multirow{3}{*}{$\begin{array}{c}4 \\
\text { encontros }\end{array}$} \\
\hline & Diretor de Supply Chain e TI & Não estava na empresa & 1 encontro & \\
\hline & $\begin{array}{l}\text { Gerente de Tecnologia da } \\
\text { Informação }\end{array}$ & Analista de Sistemas. & 1 encontro & \\
\hline CropNutri & \begin{tabular}{|ll} 
Country & Manager \\
Fertilizantes & \\
\end{tabular} & Gerente de Planejamento & 1 encontro & 1 encontro \\
\hline TechTissue & $\mathrm{CIO}$ & Gerente de Sistemas & 2 encontros & $\begin{array}{c}2 \\
\text { encontros }\end{array}$ \\
\hline
\end{tabular}

Figura 4 - Entrevistados na pesquisa.

As entrevistas foram realizadas individualmente com cada entrevistado e tiveram suas respostas anotadas. Essas anotações, após compiladas foram encaminhadas para os respondenteschave de cada empresa para serem revisados e validados, não tendo havido discordâncias significativas nos conteúdos finais. Esse procedimento é parte do teste de confiabilidade conforme sugerido por Yin (2005).

Ressalva-se que apesar do reduzido número de entrevistados oferecidos pela CropNutri e pela TechTissue comparativamente à HoliBible e InovativEduc, os objetivos da pesquisa foram alcançados, principalmente considerando-se a posição de liderança dos entrevistados, o nível de envolvimento nos projetos do ERP e a qualidade das entrevistas obtidas com cada um.

\section{Apresentação e Discussão dos Resultados}

\subsection{Liderança corporativa (Constructo 1)}

Complementar à variável de unidade de comando do modelo conceitual, o apoio direto de diretores no projeto, determinado pelo grau de interesse e conhecimento de cada etapa, traduz-se no nível de engajamento e interesse dos usuários em relação aos resultados do projeto.

A participação dos dirigentes da HolyBible no projeto de implementação do ERP foi ativa. Montou-se um comitê gestor do qual participaram os diretores e o presidente. O CIO esteve totalmente envolvido no projeto, tanto na montagem da estratégia quanto no controle diário das tarefas de cada consultor. Vale notar que a maioria dos funcionários envolvidos com o projeto ainda está na empresa e no mesmo cargo. O coordenador do ERP estima que mais de $90 \%$ dos funcionários envolvidos no projeto permanece na empresa e no mesmo cargo.

Pode-se observar que os usuários detêm conhecimento em relação ao projeto, aos processos configurados no ERP e também em relação às razões pelas quais alguns processos funcionarem com mais eficiência do que outros. Dessa forma, o reconhecimento dos benefícios alcançados e dos potenciais benefícios a alcançar é generalizado entre os usuários.

O gerente funcional do projeto de implementação da InovativEduc foi o próprio diretor de operações da empresa, mas este fato não significou o envolvimento de toda a diretoria executiva. Os demais diretores tinham pouco ou quase nenhum envolvimento, limitando-se a reuniões mensais de posicionamento em relação ao andamento geral do projeto. Esse quadro resultou em uma distorção nos objetivos da implantação e da gestão de operações, uma vez que o diretor de operações imprimia um envolvimento detalhado e incompatível com as atribuições de diretor, trazendo baixa qualidade, tanto na gestão das operações, como na gestão do projeto.

Cabe ressaltar que, tal como na implantação das práticas do TQM, na implantação de um conjunto de práticas de gestão que afetam a maneira com que as atividades serão realizadas e também a maneira com que o relacionamento entre as atividades irá ocorrer (como ocorre no processo de implantação do ERP), o compromisso do executivo de maior nível hierárquico é determinante para o 
sucesso do projeto. Percebe-se, assim, no caso da InovativEduc uma estrutura de processos mais robusta no que diz respeito à área de operações, mais especificamente a área de produção.

Diferentemente da HoliBible, na CropNutri a diretoria teve pouco envolvimento no projeto de implementação, realizando intervenções apenas quando era necessário tomar alguma decisão de âmbito corporativo. Porém, é importante enfatizar a liderança efetiva exercida pelo executivo de maior nível hierárquico no Brasil. O gerente de planejamento declarou que na reunião de início oficial do projeto de implementação, o presidente tomou toda a responsabilidade sobre o projeto determinando que fosse cumprido conforme planejado. Assim, o projeto foi realizado conforme o planejado, prazo e custos.

Em relação aos demais funcionários que participaram do projeto, todos permanecem na empresa, sendo que apenas o gerente de operações mudou de cargo, promovido a Country Manager da Operação de Fertilizantes para a subsidiária brasileira reportando-se diretamente ao presidente da subsidiária.

Apesar de não haver dedicação exclusiva dos funcionários com o projeto, todos se apresentaram bastante comprometidos e com alto nível de relacionamento com os consultores, postura essa garantida por dois fatores: liderança do presidente e cultura da empresa voltada a responsabilidade. Esses dois fatores garantiram um bom nível de absorção de conhecimentos tanto da parte dos consultores em relação aos processos da empresa, refletindo no bom nível de configuração do ERP, quanto na transferência de conhecimento dos consultores para os usuários em relação à operação com o sistema dentro de cada processo de negócio, trazendo sucesso a etapa de implantação.

$\mathrm{Na}$ TechTissue também houve pouco envolvimento da diretoria, o que pode explicar o baixo comprometimento dos usuários das áreas da empresa com o projeto. Contudo, historicamente a empresa apresenta baixa rotatividade e a maioria dos funcionários da época da implementação ainda permanece na em suas posições. O CIO esclareceu que a cultura da empresa é pautada na qualidade do ser humano, o que poderia se esperar maior comprometimento e envolvimento dos funcionários. Todavia, o baixo comprometimento da diretoria com o projeto determinou pouco interesse dos usuários, além de dificuldades para o gerente de projetos em conseguir respostas e engajamento por parte dos usuários.

\subsection{Orientação Estratégica (Constructo 2)}

A HolyBible é departamentalizada por produto e em seu relacionamento externo a departamentalização é considerada por região e por cliente. O coordenador do ERP e o CIO afirmam existir um processo de planejamento estratégico de periodicidade anual com revisão a cada 5 anos, contudo, não há nenhuma conexão das diretrizes firmadas nesse processo com o direcionamento tático da empresa, que se guia em função exclusiva do mercado. Há, no entanto, uma exceção para essa desconexão. No planejamento estratégico, a empresa propõe direcionar uma parcela de recursos para obras de caridade, fazendo doações de livros e também produzindo produtos deficitários na relação custo e resultado atendendo assim as suas finalidades filantrópicas. A programação da produção é diretamente afetada por essa diretriz, criando ordens de produção para atendimento específico dessa estratégia.

Cabe alertar que a questão colocada tem intenção de identificar processos formais de conexão dos níveis estratégico, tático e operacional, porém, aqui foi possível constatar a intervenção direta da diretoria na estrutura do plano tático sem um processo formal de conexão dos níveis estratégico e tático.

Na contramão das opiniões externadas pelo CIO e coordenador do ERP, o gerente industrial afirma não existir o processo de planejamento estratégico e ainda, para o gerente de logística esse planejamento existe, mas ele nunca teve acesso. Acrescentou ainda que está sendo formada uma comissão de gerentes para realizar um alinhamento de diretrizes táticas e estratégicas com as diretorias.

Quando questionados a respeito da prática de processo formal de planejamento tático, as opiniões foram unânimes, existe um processo de planejamento tático em que é definido o mix de produtos a serem produzidos mensalmente. A partir da implantação do ERP esse processo foi intensificado e sua abrangência ampliada. Nesse planejamento são consideradas as quantidades a serem produzidas, os preços a serem praticados para cada produto e família de produtos e a quantidade 
de cada produto que deverá estar disponível nos estoques das lojas e das áreas de estocagem que alimentam as lojas, áreas essas geralmente na mesma estrutura de armazém das fábricas. Esse processo determina uma meta para as vendas, porém, está muito mais orientado à operação da empresa do que ao estabelecimento de táticas propriamente ditas. De fato, não são adotadas táticas de competição ou de otimização dos processos da empresa visando diminuição de custos e aumento de lucratividade. Em resumo, o gerente de logística explica que existe um planejamento tático em função da carteira de pedidos de vendas.

Através da área de programação da produção, as diretrizes do plano tático mensal direcionam a criação manual das ordens de produção. Vale ressaltar que a empresa não utiliza os módulos de planejamento (MRP e MRP II) nessa tarefa. O gerente industrial acrescenta que a HolyBible opera reagindo às dificuldades do dia a dia. Mais ainda, afirmou não existir uma conexão das ações operacionais com as diretrizes táticas e estratégicas. No que diz respeito a metas periódicas definidas para cada colaborador/profissional, na opinião do coordenador do ERP, do gerente industrial e do gerente de logística, não existe tal processo. Apenas para a força de vendas, mesmo assim, na forma de quotas. Assim, não há processo formal de avaliação de desempenho, apenas para a equipe de vendas há o pagamento de prêmios por vendas. Há também pagamento de bônus para todos os funcionários, de acordo com os resultados de cada unidade. A InovativEduc não possui a cultura de planejar suas atividades, não foi encontrada nenhuma evidência que pudesse atestar alguma orientação estratégica. O diretor de Supply Chain e TI e o coordenador do ERP afirmaram não existir um processo de planejamento estratégico de longo prazo para orientar as ações da empresa. Há um processo de planejamento estratégico de periodicidade trimestral que envolve a determinação das metas de produção em função da projeção das vendas para o próximo período. É pertinente afirmar que o processo descrito evidencia a existência de um plano de ação integrado entre as áreas de vendas e de produção, mas que não proporciona diretrizes estratégicas para a empresa como um todo.

A InovativEduc é departamentalizada por produto nas áreas da administração corporativa, porém, orienta suas áreas comerciais por mercado. Essa dicotomia acaba dificultando o sincronismo de objetivos entre as áreas de produção e comercial por falta da existência de objetivos estratégicos que norteiem toda a empresa. Uma evidência dessa situação é verificada pela existência do plano tático trimestral gerado em consonância pelos departamentos de vendas e produção e traduzido em ações operacionais a partir do processamento das previsões de vendas realizadas em planilhas de cálculos, e pelas fases do planejamento de da suíte de manufatura do ERP (MPS e MRP). Embora a produção seja dependente desse processo, as ações praticadas pela área de pós-vendas desprezam o plano existente, impactando negativamente a produtividade e o sincronismo da produção com o plano existente, na medida em que desviam itens acabados do processo para atendimento direto de reinvindicações pontuais dos clientes, afetando com isso as informações de empenhos de quantidades de produto acabado para pedidos de vendas, ação essa vinda do processo de execução do MRP.

De outro lado, as ordens de compras geradas pela fase MRP, não são efetivamente consideradas no processo de compras, mas sim como referência numérica para os compradores, que possuem uma margem de valores e quantidades para negociar com os fornecedores, face às dificuldades em relação a certas matérias primas específicas. Esse fato também provoca distorções nos níveis de estoques tornando seu custo elevado para o tipo de operação.

$\mathrm{Na}$ CropNutri, a departamentalização é realizada por região agrícola produtivae há um processo formal de planejamento estratégico, que é anual com visão para 5 anos. O country manager informou que as diretrizes do planejamento estratégico são derivadas para o nível tático, mas o ERP não é utilizado para esse propósito. Já as diretrizes do planejamento tático são derivadas para o nível operacional através do ERP, na medida em que todas as ordens de compras, ordens de produção e pedidos de vendas são criados dentro do ERP a partir das diretrizes do planejamento tático derivado do estratégico.

Para a CropNutri as questões de orientação estratégica estão mais definidas do que nas empresas HolyBible e InovativEduc. Existe conexão das ações operacionais com as diretrizes táticas e estratégicas, onde a operação é totalmente subordinada ao ERP e as métricas de aferição do planejado versus executado/realizado são alimentadas a partir do ERP, completa o country manager.

Em relação à força de trabalho, não existem metas periódicas claramente definidas para cada colaborador, mas há processo formal de avaliação de desempenho. Todos os níveis da empresa são avaliados anualmente a partir de metas numéricas vinculadas com o desempenho da matriz no país 
(subsidiária brasileira). Pelo exposto, conclui-se não haver conexão das metas periódicas individuais com as diretrizes estratégicas da empresa.

A TechTissue apresenta uma configuração em que a departamentalização é considerada por tecnologias de produtos - espalmados, calandrados, estrudados e coagulados. Dentro dessas tecnologias há a divisão é realizada por mercados.

A orientação estratégica da empresa parece mais definida do que a situação das empresas HolyBible e InovativEduc. Segundo o CIO, há processo formal de planejamento estratégico, com periodicidade anual para 5 anos. As diretrizes do planejamento estratégico são derivadas para o nível tático e existe processo formal de derivação.

O entrevistado também esclarece existir processo formal de planejamento tático, com periodicidade trimestral e revisões mensais. As diretrizes do planejamento tático são derivadas para o nível operacional, mas a empresa não utiliza o ERP nesse processo. Importante destacar que há conexão das ações operacionais com as diretrizes táticas e estratégicas. Há gestão por indicadores de desempenho com premiação por desempenhos diferenciados.

\subsection{Modelo de Gestão de Operações (Constructo 3)}

O coordenador do ERP entende que a estratégia utilizada pela produção da HolyBible seja a de MTS (make-to-stock).

Já gerente industrial afirma que é MTO (make-to-order), trabalhou seja, sob encomenda. A princípio, o MTS é adotado, mas para o tipo de vendas chamado "Afinidade" a estratégia MTO é predominante. Em resumo, na HolyBible a estratégia de produção não é ponto pacífico.

Em se tratando de tipo de produção, o coordenador do ERP da HolyBible explica que a prática de manufatura discreta foi utilizada como configuração básica da suíte de manufatura do pacote ERP, embora a manufatura por processo seja, aparentemente, a mais adequada ao processo produtivo da produção gráfica. Para a encadernadora, a funcionalidade de manufatura discreta atende ao tipo de produção existente.

A variedade de produtos acabados tende a se modificar durante o ciclo anual de fabricação. No momento das entrevistas, o coordenador do ERP e o gerente industrial apontaram 800 produtos ativos (pode-se entender como variações da linha padrão, dado o grau de adaptação aos requisitos dos clientes que cada produto pode sofrer). O gerente de logística esclareceu que ao todo são 560 produtos para o mercado nacional e 320 para o mercado de exportação. Em média, a produção gira em torno de 750 mil unidades por mês. Esse número, no entanto, depende de vários fatores e pode oscilar com tendências sazonais atingindo marcas de 1,2 milhão de unidades em um mesmo mês. Anualmente são fabricadas cerca de nove milhões de unidades.

Todos os entrevistados da InovativEduc afirmaram que a empresa não adota nenhum modelo formal de gestão de operações. As iniciativas de minimizar os erros de controles da produção e de gestão do processo produtivo são realizadas através do método de "tentativa e erro", sem nenhum embasamento técnico ou científico, nem tão pouco formalização de resultados, sejam eles oriundos de acertos ou de erros.

Assim como a InovativEduc, a CropNutri não adota modelo formal de gestão de operações. A produção é caracterizada, segundo o entrevistado, por make to order (MTO) e assembler to order (ATO). Isto é, a empresa só fabrica mediante pedido de vendas e também elabora fórmulas conforme especificação do cliente. $O$ country manager afirma ser essa uma condição do mercado.

O processo produtivo pode ser caracterizado como por lotes ou bateladas, sendo que entre as fórmulas padrão e solicitações específicas de clientes, há cerca de 100 SKU. A operação da CropNutri atinge o limite médio de 500 toneladas de fertilizantes por dia, considerando os recursos disponíveis na época das entrevistas.

No que diz respeito à estratégia de produção, as plantas da TechTissue localizadas no Sudeste, Sul e Nordeste utilizam a estratégia make to order (MTO), produzindo apenas mediante a existência de pedidos de vendas. Já a planta de sintéticos, localizada no interior de São Paulo, pratica a estratégia make to stock (MTS), isto é, produz para estoque. 
De qualquer forma, toda a produção é do mesmo tipo, produção por batelada, diferenciada pela tecnologia aplicada. A variedade de produtos é grande, 18 mil produtos ativos, com um volume de 6 milhões de metros por mês.

Cabe notar que nenhuma das empresas adota qualquer modelo de gestão de operações que tenha abrangência sobre a integração e controle dos processos de negócios. Esse posicionamento suscita a relação com o modelo proposto, uma vez que diversos problemas relatados na área de operações têm vínculo direto com a ausência de uma estrutura robusta gestão de operações. A HolyBible, por exemplo, entende ser necessário implementar a metodologia Lean para proporcionar formas de ajustar seus processos diante dos problemas crônicos de falta de disciplina nas atividades burocráticas da produção. Avança também no esforço de implementar a metodologia do Kaizen. Contudo, parece não perceber que esses métodos irão requerer maior amplitude de ações para que funcionem da forma esperada. A empresa InovativEduc relata uma série de problemas relacionados à gestão de operações. Alguns problemas citados estão vinculados à ausência de método de gestão de operações.

As empresas CropNutri e TechTissue possuem seus processos produtivos bem estabilizados. Ambas relataram capacidade produtiva inferior a demanda em boa parte de seus ciclos anuais sem, contudo, empreender esforços formais de otimização do parque instalado.

\subsection{Adaptabilidade do ERP utilizado (Constructo 4)}

As quatro empresas participantes do estudo utilizam o pacote ERP EnterpriseOne (E1) da JD Edwards/Oracle e implementaram as suítes Financeira, Distribuição \& Logística e Manufatura.

Cada empresa teve seu próprio contexto para aquisição e implementação do ERP. Esses contextos são apresentados e descrevem o ambiente e as motivações para a escolha e implementação do ERP.

A HolyBible, além de adquirir o pacote ERP E1 também implantou o pacote CRM SIEBEL da mesma fabricante americana do ERP. A diretoria da empresa decidiu adquirir um pacote ERP que possuísse funcionalidades suficientes para os requisitos de controle e de previsão de crescimento da empresa. O gerente de logística destacou ainda que a partir de uma auditoria conduzida pela empresa Deloitte foram apontados diversos pontos fracos na gestão da empresa e isso motivou a decisão da implementação de um software ERP. O processo de escolha do pacote ocorreu durante o ano de 2009 quando foi contratada uma consultoria externa para conduzir os trabalhos de seleção.

A empresa apresenta taxa de crescimento bastante acentuada e com isso, um aumento significativo no grau de complexidade dos controles necessários para uma operação eficiente. Antes do ERP a empresa utilizava dois pacotes de mercado não integrados, chegando ao ponto de imprimir listagens de um sistema para proceder à entrada de dados no outro sistema via digitação. Os dois sistemas anteriormente existentes também não atendiam às necessidades de controles que a empresa exigia em seus padrões de gestão, embora não faça uso de nenhuma metodologia formal de gestão, além de estarem tecnologicamente bastante desatualizados.

$\mathrm{O}$ gerente de logística enfatizou que o controle do chão de fábrica figura como sendo o segundo principal motivo da decisão por um ERP. Importante destacar que a literatura coloca a integração como um dos importantes benefícios esperados com a implementação do ERP (RANGANATHAN; BROWN, 2006; DAVENPORT, 2000; SNIDER; SILVEIRA; BALAKRISHNAN, 2009). Havia a necessidade de promover incrementos na velocidade de atendimento aos clientes, além da necessidade de disponibilizar os resultados do período para a diretoria a título de dar conhecimento relativo às metas alcançadas. Dessa maneira, foram adquiridas as suítes: Financeira, Distribuição \& Logística, Manufatura do ERP JD Edwards, além do módulo de Automação da força de vendas do software CRM Siebel.

Não houve consenso em relação ao projeto de implementação pois parte dos diretores entendia ser necessário implementar inicialmente o CRM e outra parte entendia que o ERP deveria ser a base inicial.

Cabe esclarecer que tecnicamente os cadastros básicos de materiais (inclui produtos acabados), clientes, transportadoras, representantes, funcionários, entre outros necessários nos dois sistemas deveriam ter o controle em um só sistema. Algumas informações desses cadastros não são 
necessárias no ERP e outras não são necessárias no CRM em função de sua dimensão e categoria, inclusive considerando a natureza de cada sistema. Nessa condição, um dos sistemas deveria ser o único ponto de entrada das informações básicas de cada cadastro para os dois sistemas e, cada sistema individualmente deveria estar provido de mecanismos que possibilite complementar as informações pertinentes à necessidade de cada um. Portanto, a discussão referente a qual sistema (ERP ou CRM) implementar primeiro e qual deveria ser implantado posteriormente, não deveria ser o foco central da preocupação e sim como realizar a sequência dos processos de negócios entre os dois sistemas de maneira coordenada para que a empresa pudesse ser atendida eficientemente pelas funcionalidades dos aplicativos.

De acordo com o coordenador do ERP e com o gerente industrial, houve definição e publicação dos resultados esperados pela diretoria para toda a empresa. Houve a criação de um grupo de comunicação que se ocupou de divulgar as definições e resultados esperados com a adoção do pacote. Esse processo de comunicação incluiu práticas de construção de espírito de equipe que possibilitou um melhor engajamento dos funcionários com o projeto. A construção do espírito de equipe em relação a um projeto que irá trazer mudanças na forma de trabalho das pessoas é considerada na literatura um dos fatores de sucesso de projetos desse tipo (JUN; CAI; SHIN, 2006; SNIDER; SILVEIRA; BALAKRISHNAN, 2009; SCHNIEDERJANS; KIM, 2003).

Para o projeto de seleção do ERP conduzido pela consultoria externa, foi montado um comitê gestor composto pelos diretores e principais formadores de opinião da empresa. A metodologia e a coordenação dos trabalhos foram realizadas pela consultoria. Foram conduzidas reuniões com as diversas áreas da empresa para identificar as principais necessidades de cada processo de negócio operado. A partir desse trabalho foi elaborado um documento chamado de RFI (Request For Information) contendo os requisitos de negócios da empresa naquele momento, que foi enviado a diversas empresas fabricantes de ERP nacionais e internacionais. Houve a tabulação das respostas de cada fabricante, com estes dados foram chamadas a participar do processo as três empresas melhores pontuadas para apresentar seus produtos e suas propostas de custos. As apresentações foram realizadas para os grupos de trabalho de cada área que tinham a incumbência de pontuar item a item da RFI construindo assim um documento de seleção pontuado. Essa tarefa garantia a seleção da opção que oferecesse a melhor aderência aos requisitos de negócios da HolyBible sem ferir os fundamentos conceptivos do ERP, que segundo Snider; Silveira e BALAKRISHNAN (2009) é um dos fatores de sucesso na adoção de um ERP.

Depois de ponderadas as pontuações de cada pacote concorrente, foram realizadas reuniões do comitê para discutir e aprovar a escolha do pacote vencedor. O projeto foi patrocinado pelo principal executivo da empresa com o respaldo do conselho de administração. De fato, essa é considerada uma das premissas para o sucesso de projetos relacionados à gestão da empresa (JUN; CAI; SHIN, 2006), como é o caso desse tipo de projeto.

Para a InovativEduc, a implementação do ERP tinha um objetivo específico, porém, não estruturado: o presidente acreditava que a tecnologia da informação era um redutor de custos operacionais e um facilitador da administração das operações. Assim, foram adquiridas licenças para as suítes: Financeira (FIN), Distribuição \& Logística (D\&L) e Manufatura (MFG) do ERP.

Importante destacar que não houve processo formal para aquisição do pacote, mas houve consenso entre o diretor de operações e o presidente em relação à decisão de adquirir o software composto pelas suítes anteriormente citadas. Também não houve a divulgação formal para os funcionários da empresa e para os consultores externos responsáveis pelo projeto de implementação, dos principais objetivos e dos resultados esperados pela diretoria com a implementação do pacote. Mesmo assim, o diretor de operações empreendeu sua implementação, ocupando o papel de gerente do projeto.

O processo de aquisição foi conduzido diretamente pelo diretor de operações sem a utilização de uma metodologia que garantisse a qualidade da escolha. $O$ diretor assistiu apresentações dos pacotes de maior projeção no mercado, tendo selecionado aquele que the pareceu melhor atender à relação funcionalidade e preço, considerando também o nível de aderência das funcionalidades disponíveis no pacote, ao que ele entendia como sendo as necessidades futuras dos processos de negócios da empresa. Feita a seleção, convidou o presidente para assistir uma apresentação sobre as principais características e possibilidades de benefícios relativos ao pacote selecionado, a título de ser formalizada a decisão final de compra. 
$\mathrm{Na}$ ocasião, o orçamento para a compra das licenças e para o projeto de implementação do ERP, superava em mais de $100 \%$ o faturamento da empresa. Esse quadro era esperado uma vez que a empresa encontrava-se em fase inicial de operação, porém, afetou a decisão relativa ao momento ideal para proceder a implementação, atrasando em mais de três anos a decisão de iniciar o projeto, embora já tivesse adquirido as licenças. Em 2009 a CropNutri decidiu pela implementação do ERP na operação Brasil de fertilizantes. Embora a empresa já utilizasse o pacote em suas operações na matriz americana e subsidiárias europeias, foi concedido à subsidiária brasileira o direito de escolha de qual pacote implantar. Essa liberdade em relação à matriz apoiava-se no fato da subsidiária brasileira estar sendo inaugurada. No entanto, a matriz ofereceu à possibilidade da subsidiária brasileira ser a pioneira na implementação da nova versão do pacote que a fabricante americana Oracle havia disponibilizado ao mercado, estabelecendo, a partir do projeto brasileiro, diretrizes para a realização da atualização do software em todo grupo.

A principal motivação para a implementação do pacote era iniciar a operação da empresa com seus processos integrados e controlados através de um software ERP. Também foi fator de motivação o fato de todos os concorrentes possuírem um ERP implantado. Na decisão de adoção do ERP houve consenso entre os diretores da subsidiária brasileira, contudo, a decisão final foi da matriz da empresa americana. O resultado esperado com a adoção do ERP era o seu funcionamento frente aos processos da empresa de forma sincronizada e com suporte efetivo à operação.

O processo formal de seleção foi comandado pelo gerente de operações local e um consultor da matriz americana. Houve visitas do CIO e CFO mundiais para a fase decisiva da escolha do pacote e da empresa de consultoria que faria a implementação do pacote. Uma vez selecionado o pacote e a empresa de consultoria para a implementação, reuniões de negociação e de aprovação foram realizadas para fechamento do processo de seleção. Cabe destacar que o patrocinador do projeto de implementação foi o presidente da subsidiária brasileira (comando único das duas operações no Brasil - Grãos e Fertilizantes), que dispôs de $0,5 \%$ do faturamento anual para o projeto.

A TechTissue, no ano de 2001, tomou a decisão de implantar um ERP, sendo que em meados de 2002 foi iniciado o projeto de implementação, que foi finalizado somente em 2004.

A aquisição e implementação do ERP teve como principal motivador o desenvolvimento organizacional, com a liderança do projeto tendo ficado a cargo do CIO (gerente de sistemas na época) e do gerente organizacional. Decisão consensual entre os diretores da empresa, a expectativa do projeto era obter um processo organizado e suportado pelo ERP, mas a implementação ocorreu com diversos problemas causados por inexperiência da empresa com projetos desse tipo e por falta de competência dos consultores externos em relação ao ERP e aos processos de negócio. Para a escolha, houve um processo formal de seleção do software baseado em uma metodologia de uma consultoria especializada neste tipo de processo. Destaca-se que o patrocinador do projeto era o diretor financeiro e que não havia um orçamento fechado para a execução do projeto.

A implementação de um software ERP deveria possibilitar que todos os processos operacionais das empresas tivessem suportem, na mesma base de informações, o que pode garantir a integração entre os departamentos e diferentes processos, além de possibilitar controle e visibilidade da operação como um todo. $\mathrm{O}$ objetivo é trazer vantagem competitiva à empresa imprimindo velocidade nos processos de produção e atendimento aos clientes. Esses benefícios eram esperados pela direção da empresa, porém, os problemas ocorridos impediram qualquer obtenção de resultado.

Diante das dificuldades e da frustração dos resultados, a empresa decidiu retroceder e reiniciar o projeto de implementação desde o princípio. Porém, após os problemas vivenciados, a experiência da empresa em relação às necessidades e pré-requisitos para o êxito do processo de implementação já havia sido adquirido. Foi contratada outra empresa de consultoria sob critérios mais rigorosos, o patrocínio do projeto foi recebido do diretor de operações de uma das unidades fabris (esse cargo corresponde ao diretor geral da unidade) e a estratégia do projeto foi alterada de "Big Bang" para "Small Bangs", ou seja, no projeto inicial adotou-se a estratégia de implementar o ERP colocando em operação toda a empresa no mesmo momento (Big Bang). No segundo projeto, a estratégia adotada realizava o início de utilização em cada unidade, separadamente, uma depois a outra (Small Bangs). Cabe ressalvar que cada estratégia possui suas vantagens e desvantagens, ficando esse tipo de decisão vinculada a características específicas de cada projeto, determinando o que seria mais vantajoso caso a caso.

A figura 5 resume os principais pontos de cada caso estudado. 


\begin{tabular}{|c|c|c|c|c|}
\hline Constructos & $\begin{array}{c}\text { Liderança e } \\
\text { Comprometimento da } \\
\text { alta administração } \\
\end{array}$ & Planejamento Estratégico & $\begin{array}{c}\text { Modelo de Gestão de } \\
\text { Operações }\end{array}$ & Adaptabilidade do ERP \\
\hline Variáveis / Questões & $\begin{array}{c}\text { Unidade de Comando } \\
\text { Corporativo }\end{array}$ & Direcionamento Estratégico & Estrutura de Operações & $\begin{array}{c}\text { Aderência dos fundamentos do } \\
\text { ERP à Linha de negócio da } \\
\text { empresa } \\
\end{array}$ \\
\hline Relação causal & $\begin{array}{l}\text { Apoio da diretoria às } \\
\text { iniciativas corporativas }\end{array}$ & $\begin{array}{c}\text { Direcionamento coordenado } \\
\text { dos esforços com conexão } \\
\text { entre os níveis Corporativo, } \\
\text { Tático e Operacional } \\
\end{array}$ & $\begin{array}{l}\text { Processos de negócios } \\
\text { eficientes e consolidados }\end{array}$ & $\begin{array}{c}\text { Configuração do ERP condizente } \\
\text { com os processos de negócios ao } \\
\text { longo do tempo }\end{array}$ \\
\hline HolyBible & \begin{tabular}{|} 
Liderança estratificada \\
impediu a iniciativa \\
corporativa de implementar \\
método de planejamento \\
da podução
\end{tabular} & $\begin{array}{l}\text { Inexistência de Planejamento } \\
\text { Estratégico dificultou a visão } \\
\text { global dos benefícios de } \\
\text { implementação do } \\
\text { planejamento da produção }\end{array}$ & $\begin{array}{l}\text { Com planos de implementar } \\
\text { metodologias de gestão de } \\
\text { operações (Lean e Kaizen), } \\
\text { não considerou as } \\
\text { necessidades para projetos } \\
\text { dessa natureza }\end{array}$ & $\begin{array}{l}\text { Realizaou o projeto de seleção e } \\
\text { escolha da forma correta } \\
\text { garantindo boa aderência do ERP } \\
\text { aos processos de negócios. } \\
\text { Sendo implementação recente, } \\
\text { está percebendo a necessidade de } \\
\text { gestão do ciclo de vida do ERP } \\
\text { com reavaliações periódicas }\end{array}$ \\
\hline InovativEduc & \begin{tabular}{|c|} 
Liderança estratificada \\
gerando dificuldades na \\
integração dos processos \\
de produção e atendimento \\
aos clientes. Projeto de \\
implementação com foco \\
demasiado nos módulos de \\
PDM, SFC e MRP I da \\
suíte de MFG em \\
detrimento das demais \\
suítes.
\end{tabular} & $\begin{array}{l}\text { Inexistência de Planejamento } \\
\text { Estratégico impedindo a } \\
\text { integração dos esforços em } \\
\text { prol do desenvolviemnto } \\
\text { organizacional, aproveitamento } \\
\text { de oportunidades e } \\
\text { minimização de ameaças. }\end{array}$ & \begin{tabular}{|c|} 
Inexistência de processo de \\
gestão de operações. Cultura \\
da empresa sem conceitos de \\
disciplina corporativa. \\
Nenhum processo produz \\
resultados confiáveis. \\
Implantação do TQM iria \\
garantir a quebra de \\
paradigmas proporcionando o \\
desenvolvimento \\
organizacional. Uso do MRP \\
I não propicia os benefícios \\
possíveis devido à \\
indisciplina na atualização \\
dos dados relacionados a \\
esse processo. \\
\end{tabular} & $\begin{array}{l}\text { ERP selecionado antes da } \\
\text { operação da empresa necessitar. } \\
\text { Foco da seleção nos processos } \\
\text { de produção garantiu bom nível } \\
\text { de aderência. Implementação } \\
\text { realizada sem revisão dos } \\
\text { processos o que impediu o bom } \\
\text { aproveitamento do ERP como } \\
\text { um todo. Ausência de processo } \\
\text { de revisão de aderência e } \\
\text { treinamento de usuários } \\
\text { agravando quadro de baixa } \\
\text { confiabilidade das informações } \\
\text { do ERP. }\end{array}$ \\
\hline CropNutri & \begin{tabular}{|c|} 
Liderança do principal \\
executivo bastante efetiva. \\
Todo o projeto de escolha \\
e aquisição, implementação \\
e a fase de implantação \\
decorreram conforme o \\
planejado. Percepção de \\
retorno e benefícios são \\
claras e de acordo com o \\
esperado
\end{tabular} & $\begin{array}{l}\text { Realiza o planejamento } \\
\text { estratégico e seu resultado } \\
\text { direciona os planos táticos e } \\
\text { operacionais. Não utiliza o } \\
\text { ERP nessas atividades o que } \\
\text { obstrue a visão de valor dos } \\
\text { módulos de planejamento da } \\
\text { suíte de MFG do ERP }\end{array}$ & $\begin{array}{l}\text { Não utiliza nenhum modelo } \\
\text { de gestão de operações. Com } \\
\text { isso não há uma gestão de } \\
\text { processos formal, o que } \\
\text { também obstrue a visão de } \\
\text { benefícios da utilização do } \\
\text { planejamento da suíte de } \\
\text { MFG. Contudo, a disciplina } \\
\text { existente permite que os } \\
\text { processos sejam executados } \\
\text { de forma correta e integrada. }\end{array}$ & $\begin{array}{c}\text { Processos de seleção e aquisição } \\
\text { realizados com metodologia } \\
\text { formal, garantindo bom nível de } \\
\text { aderência do ERP aos processos } \\
\text { de negócios. Implementação } \\
\text { realizada sem grandes } \\
\text { dificuldades garantindo a fase de } \\
\text { implantação adequada. } \\
\text { Percepção de benefícios é bem } \\
\text { clara, mas empresa não realiza } \\
\text { processos de revisão e } \\
\text { reciclagem de aderência. Prjeto } \\
\text { muito recente para essa lacuna } \\
\text { causar problemas mas, empresa } \\
\text { já nota os primeiros sintomas de } \\
\text { não existir processo formal de } \\
\text { revisão de aderência e reciclagem } \\
\text { de treinamentos aos usuários. }\end{array}$ \\
\hline TechTissue & \begin{tabular}{|c|} 
Primeira tentativa de \\
implementar o ERP \\
frustrada; falta de liderança \\
listada como uma das \\
razões. Segunda tentativa \\
houve sucesso; liderança \\
da diretoria listada como \\
uma das razões
\end{tabular} & $\begin{array}{c}\text { Existência de processo de } \\
\text { Planejamento Estratégico, } \\
\text { porém, a não utilização do } \\
\text { ERP para conxão dos níveis } \\
\text { tático e operacioal ao } \\
\text { estratégico, impede a visão de } \\
\text { valor do uso do planejamento } \\
\text { via ERP }\end{array}$ & $\begin{array}{c}\text { Sem modelo formal de } \\
\text { gestão, a empresa realiza a } \\
\text { gestão de operações baseada } \\
\text { na tecnologia específica de } \\
\text { cada fábrica, deixando a } \\
\text { cargo do gestor da fábrica a } \\
\text { gestão como um todo. Esse } \\
\text { posicionamento embora } \\
\text { funcione, tem seu próprio } \\
\text { modelo de planejamento, o } \\
\text { que obstrue a visão de valor } \\
\text { dos módulos de } \\
\text { planejamento do ERP. O } \\
\text { entrevistado declarou estar } \\
\text { estudando formas de } \\
\text { começar a utilizar o SCP. } \\
\end{array}$ & $\begin{array}{l}\text { A empresa realizou o projeto de } \\
\text { aquisição da forma correta, com } \\
\text { metodologia estruturada. Porém, } \\
\text { na escolha da empresa de } \\
\text { consultoria, não foi realizado um } \\
\text { processo criterioso, ocasionando } \\
\text { a 1a implementação frustrada. A } \\
\text { empresa está com planos de } \\
\text { realizar uma atualização do } \\
\text { software com re-implantação, } \\
\text { para recuperar conhecimentos } \\
\text { perdidos. Esse fato endoça o } \\
\text { modelo do trabalho onde } \\
\text { afirmamos ser necessário } \\
\text { revisões contínuas de aderência e } \\
\text { treinamento de usuários. }\end{array}$ \\
\hline
\end{tabular}

Figura 5 - análise comparativa dos casos

Cada constructo listado possui uma variável que pode assumir posições impeditivas para a empresa que deseja utilizar, com vantagens, os módulos de planejamento de materiais e recursos de produção. 
Foi possível concluir que os seguintes fatores impactam na possibilidade da empresa auferir valor no uso do MRP e MRP II:

a) A falta de liderança e unidade de comando na empresa;

b) A falta de objetivos estratégicos na empresa;

c) A falta de conhecimento das funções de planejamento e das necessidades de conexão entre o planejamento dos níveis estratégico, tático e operacional;

d) A inexistência de uma metodologia de gestão de operações;

e) $\mathrm{O}$ desconhecimento dos profissionais integrantes dos times de projetos de escolha e implementação do software, em relação às funcionalidades do ERP e as necessidades de negócios;

Percebe-se um equívoco ao se encerrar o projeto de implementação sem um método formal de reavaliação contínua da compatibilidade entre os processos de negócios existentes e as práticas configuradas no ERP.

Baseado nos casos estudados foi possível verificar que para o constructo Liderança e a falta de unidade de comando pode trazer situações em que, embora a empresa pretenda realizar a implementação dos módulos de planejamento da suíte de manufatura, a visão contrária de um diretor da empresa pode inviabilizar a aplicação dos módulos.

Constatou-se também que o direcionamento estratégico da empresa pode não relacionar os níveis estratégico, tático e operacional pela ausência de um processo formal de planejamento estratégico, o que não propicia a coordenação dos esforços da empresa para os mesmos objetivos. Essa posição impacta diretamente na percepção de valor relacionada aos módulos de planejamento, na medida que não oferece uma razão para planejar a operação, não oferece um objetivo maior.

A ausência de uma metodologia de gestão de operações que integre os esforços de cada funcionário e permita medidas de efetividade dos processos de negócios, impacta na possibilidade de integração entre os objetivos corporativos, os planos táticos e as atividades operacionais. A qualidade das relações de trabalho também foi impactada por essa ausência. Esse panorama torna precária a coordenação dos processos de negócios afetando a eficiência operacional.

Sendo o modelo proposto nesse trabalho construído a partir dos constructos elencados por Jun et al. (2006), entende-se que a implementação do TQM como revisor e consolidador dos processos de negócios da empresa e, mais do que isso, como um agente de mudança cultural que propicie à empresa quebrar paradigmas de indisciplina corporativa, faz da implantação prévia do TQM ao projeto de implementação do ERP, uma condição necessária e efetiva.

Por fim, a adaptabilidade do ERP, considerando a aderência de seus fundamentos e da forma com que foi configurado em relação às necessidades dos processos chave do negócio ao longo do tempo, pode prejudicar uma visão ampla de suas possibilidades e produzir consequências negativas no alcance dos benefícios disponíveis.

\section{Considerações Finais}

Os sistemas ERP são geralmente construídos conforme modelos de gestão que incluem relacionamentos coordenados entre atividades de diferentes áreas das empresas que compartilham as mesmas informações. São preparados para oferecer suporte a processos de negócios estruturados para cumprir tarefas determinadas e normalmente essenciais para operação da empresa. Esforços de implementação de sistemas desse tipo em ambientes onde os conceitos mencionados não se fazem presentes, exigem esforços prévios ou no mínimo concomitantes para que seja possível alcançar os benefícios aos quais o software se presta.

Os casos estudados demonstraram situações em que a presença de alguns dos constructos propostos, propiciou certa estabilidade na operação com o ERP. Também houve exemplos em que a ausência de alguns dos constructos propostos impediu qualquer estabilidade na operação com o ERP.

Uma limitação dessa pesquisa refere-se ao fato de que diante da população disponível de 60 empresas de manufatura, apenas 23 empresas haviam implementado a suíte de manufatura e dessas, apenas 9 implementaram o módulo de planejamento de materiais (MRP I), sendo que somente 3 estenderam a implementação ao módulo de planejamento de recursos de produção (MRP II).

Neste sentido, um software nascido da evolução do MRP I e depois do MRP II, parece se distanciar de seu público atual. Esse fenômeno pouco explorado parece ter sua motivação não nas 
funcionalidades oferecidas nas suítes de manufatura dos ERP, mas na lacuna de gestão de operações inerente ao conjunto dos constructos aqui oferecidos.

Outros estudos mais profundos e também de cunho estatístico serão necessários para validar numericamente aos indícios aqui levantados. Ao levantar esses indícios explorando-os com os casos aqui estudados, esperamos ter contribuído para compreensão do fenômeno e para a área de gestão de operações.

Como sugestão de estudos futuros estão aqueles de cunho estatístico possíveis de serem generalizados e também que possam medir os indícios aqui levantados. Uma sugestão seria estudar o mesmo fenômeno em empresas grandes e de atuação global para verificar se são encontrados os mesmos padrões de comportamento das PMEs aqui estudadas.

\section{Referências}

ARUMUGAM, V., OOI, K; FONG, T. TQM practices and quality management performance: An investigation of their relationship using data from ISO 9001: 2000 firms in Malaysia. The TQM Journal 20.6, pp.636-650, 2008.

BANCROFT, N. H.; SEIP, H.; SPRENGEL, A. Implementing SAP R/3: how to introduce a large system into a large organization. $2^{\mathrm{a}}$ ed., Greenwich, Manning, 1998.

BOTTA-GENOULAZ, V.; MILLET, P. A classification for better use of ERP systems. Computers in Industry, vol. 56, p. 537-587, 2005.

DAVENPORT, T. H. Mission Critical: Realizing the promise of enterprise systems. President and Fellows of Harvard College, 2000.

DAVENPORT, T. H. Putting the enterprise into the enterprise system. Harvard Business Review, p. 121-133, 1998.

DAVENPORT, T. H., SHORT, J. E. The new industrial engineering: information technology and business process redesign. Sloan Management Review, summer, v. 31 n. 4, p. 2 - 27, Mar. 1990.

EISENHARDT, K. M. Building theories from case study research. The Academy of Management Review, v. 14, n. 4, p. 532-550, out. 1989.

FIESP. Panorama da Indústria de Transformação Brasileira. Departamento de Pesquisas e Estudos Econômicos. 5a. Ed, dez. 2014.

GODOY, A. S. Introdução à pesquisa qualitativa e suas possibilidades. RAE - Revista de Administração de Empresas. v. 35, n. 2, p. 57 - 63, 1995.

HECHT, B. Choose the right ERP software. Datamation, Março, 1997.

HONG, K.; KIM, Y. The critical success factors for ERP implementation: an organizational fit perspective. Information \& Management, vol. 40, pp. 25-40, 2002.

JUN, M.; CAI, S.; SHIN, H. TQM practice in maquiladora: Antecedents of employee satisfaction and loyalty. Journal of Operations Management, vol. 24, p. 791-812, 2006.

KARLSSON, C. Researching operations management. New York: Routledge, 2009.

KONICKI, S. 12 Says: You too Nike. Information Week, vol.32, March, 2001.

KRASNER, H. Ensuring E-Business Success by Learning from ERP Failures. IT PRO IEEExplore, Jan-Fev, 2000. 
LAUDON, K. C.; LAUDON, J. P. Sistemas de Informações Gerenciais. São Paulo, Pearson, Prentice Hall, $7^{\mathrm{a}}$ edição, 2007.

LAW, C. C. H.; NGAI, E. W. T. ERP systems adoption: an exploratory study of the organizational factors and impacts of ERP success. Information \& Management, vol. 44, p. 418-432, 2007.

LOZINSK, S. Software: tecnologia do negócio. São Paulo, Imago, 1996.

MARKUS, M. L. et al. Learning from adopters' experiences with ERP: problems encountered and success achieved. Journal of Information Technology, vol. 15, p. 245-265, 2000.

McGINNIS, T. C.; HUANG, Z. Rethinking ERP success: A new perspective from knowledge management and continuous improvement. Information \& Management, vol. 44, p. 626-634, 2007.

MENDES, J.; ESCRIVÃO FILHO, E. Sistemas integrados de gestão (ERP) em pequenas e médias empresas: um confronto entre o referencial teórico e a prática empresarial. Gestão e Produção, vol. 9, n.3, p. $277-296,2002$.

NJIE, T. L.; FON, L. T.; AWOMODU, G. Top management commitment and empowerment of employees in TQM implementation. Master thesis, University College of Boras, School of Engineering, 2008.

OOI, K. TQM and knowledge management: Literature review and proposed framework. African Journal of Business Management, v. 3, n. 11, p. 633 - 643, Nov. 2009.

OOI, K.; ARUMUGAM, V.; TEH, P.; TQM Practices and its association with production workers. Industrial Management \& Data Systems, v. 108, n. 7, p. 909 - 927, Jul. 2008.

PRAJOGO, D. I.; SOHAL, A. S. TQM and innovation: a literature review and research framework. Technovation, n. 21, p. 539-558, 2001.

SCHNIEDERJANS, M. J., KIM, G. C. Implementing enterprise resource planning systems with total quality control and business process reengineering. International Journal Operations \& Production Management. v. 23, n. 4, p. 418 - 429, 2003.

SEDERA, D.; GABLE, G.; CHAN, T. Measuring Enterprise Systems Success: a preliminary model. Ninth American Conference on Information Systems, 2003.

SHAPIRO, J. F. Modeling the supply chain. Belmont: Thomson, 2007.

SHTUB, A. Enterprise Resource Planning (ERP): The Dynamics of Operations Management. Kluwer: Kluwer Academic Publishers, 1999.

SNIDER, B.; SILVEIRA, G. J. C.; BALAKRISHNAN, J. ERP implementation at SMEs: analysis of five Canadian cases. International Journal of Operations \& Production Management, vol. 29, n.1, p. 4 $-29,2009$.

SOUZA, C. A. Sistemas integrados de gestão empresarial: estudos de casos de implementação de sistemas ERP. Dissertação (Mestrado) - Faculdade de Economia, Administração e Contabilidade da Universidade de São Paulo, São Paulo, 2000.

SRIVARDHANA, T., PAWLOWSKI, S. D. ERP systems as an enabler of sustained business process innovation: A knowledge-based view. Journal of Strategic Information Systems, vol. 16, p. 51 $-69,2007$. 
VOGEL, J.; WOOD JUNIOR, T. Práticas Gerenciais de Pequenas Empresas Industriais do Estado De São Paulo: Um Estudo Exploratório. Revista de empreendedorismo e Gestão de Pequenas Empresas, vol. 1, no. 2, 2012.

VOSS, C.; TSIKRIKTSIS, N.; FROHLICH, M. Case research in operations management. International Journal of Operations \& Production Management, v. 22, n. 2, p. 195-219. 2002.

WAGNER, E. L.; SCOTT, S. V.; GALLIERS, R. D. The creation of 'best practice' software: myth, reality and ethics. Information and Organization, vol. 16, p. 251 - 275, 2006.

YIN, R. K. Estudo de caso: planejamento e métodos. Porto Alegre. Bookman, 2010.

YIN, R. K. Estudo de Casos: planejamento e métodos. Editora Bookman, Porto Alegre, $3^{\text {a }}$ edição, 2005.

ZAKUAN, N. M.; YUSOF, S. M.; SHAMSUDIN, S.; LAOSIRIHONGTHONG, T. Reflective Review of Relationship between Total Quality Management and Organizational Performance. International Conference on Mechanical \& Manufacturing Engineering, Proceedings, May 21-23, Johor Bahru, Malaysia, 2008.

ZHANG, Z.; LEE, M. K. O.; HUANG, P.; ZHANG, L; HUANG, X. A Framework of ERP systems implementation success in China: An empirical study. International Journal Production Economics, vol. 90 , p. $56-80,2005$. 